\title{
Dental Education and Dentists' Attitudes and Behavior Concerning Patients with Autism
}

\author{
Taryn N. Weil; Marita R. Inglehart, Dr.phil.habil.
}

Abstract: The number of patients diagnosed with autism spectrum disorders (ASD) in the United States has increased significantly. The objectives of this study were to explore general and pediatric dentists' professional attitudes and behavior towards patients with ASD; these dentists' perceptions of their dental education about these issues; and the relationships among their educational experiences, attitudes, and behaviors concerning patients with ASD. Survey data were collected from 162 general dentists in Michigan and 212 pediatric dentists across the United States. The results showed that 89 percent of pediatric dentists and 32 percent of general dentists treat patients with ASD. The respondents disagreed with statements indicating that their predoctoral dental education had prepared them well to treat patients with ASD. However, the better they felt prepared, the more likely they were to provide care for these patients. The frequency with which pediatric dentists said they use appropriate behavior management strategies when treating patients with ASD correlated with the quality of their educational experiences. In conclusion, given the growing number of patients with ASD, it is important to revisit dental education efforts targeted towards preparing future dental care providers for the treatment of patients with ASD and special needs.

Ms. Weil is a dental student at the University of Michigan; Dr. Inglehart is Associate Professor of Dentistry, Department of Periodontics and Oral Medicine, School of Dentistry, and Adjunct Associate Professor of Psychology, Department of Psychology, College of Literature, Science, and Arts, University of Michigan. Direct correspondence and requests for reprints to Dr. Marita Inglehart, Department of Periodontics and Oral Medicine, School of Dentistry, University of Michigan, 1011 North University Avenue, Ann Arbor, MI 48109-1078; 734-763-8073 phone; 734-763-5503 fax; mri@umich.edu.

Keywords: autism spectrum disorders, access to dental care, dental education, professional attitudes, professional behavior, special needs patients

Submitted for publication 4/20/10; accepted 6/25/10

$\mathrm{T}$ The U.S. surgeon general's report on oral health documented that specific groups of U.S. citizens have disproportionately large amounts of oral disease and problems with access to oral health care. ${ }^{1}$ Patients with special health care needs were one of these underserved populations. One specific subgroup of these patients are patients with autism spectrum disorders (ASD). Kanner introduced the term "autism" in 1943 when he described a group of adolescents who all shared the same characteristics of impaired social interactions and communication as well as repetitive behavior. ${ }^{2}$ The DSM-IV, TR, described the broader category of ASD, which includes autism, not otherwise specified pervasive developmental disorders (PDD-NOS), and Asperger's disorder. ${ }^{3}$ This new approach to diagnosing this disease may be one contributing factor that explains the recent increase in the prevalence of ASD. ${ }^{4}$ For example, the Autism and Developmental Disabilities Monitoring Network reported in 2007 that the average rate of ASD is one in 150 , or 6.6 per 1,000 eight-year-olds. ${ }^{5,6}$ In addition, males are four times more likely than females to be affected by ASD. ${ }^{7}$

Patients with ASD have a normal life expectancy and therefore need dental care throughout their lifetimes. However, research has shown that many general dentists do not accept patients with ASD. Dao et al. found, for example, in 2005 that 67 percent of the general dentists surveyed would not accept any adults with autism and that nearly 60 percent would not provide care for pediatric patients with autism. ${ }^{8}$ The reasons for these low percentages of general dentists who accept patients with ASD might be related to the three sets of symptoms that characterize these patients and that might require special behavior management strategies when providing care for them. These symptoms are related to communication issues, impairment of social interactions, and aversion to change and repetitive, stereotypical behavior patterns. ${ }^{9}$ Each of these three sets of symptoms has a wide range of severity levels, which may be different for each patient with ASD. ${ }^{10}$ However, these three defining symptoms of ASD can have a profound impact on the way dentists can provide dental treatment for these patients.

Problems with communication appear in many ways among these patients. For example, 40 percent of children with ASD are completely nonverbal. ${ }^{11}$ Some of these children not only lack the desire to communicate, but do not make any compensatory efforts such as using gestures. ${ }^{10}$ Other children and adults with ASD may have some abilities to speak, 
but they may not be functional or fluent. ${ }^{10}$ Speech in these patients can also sound as if it were scripted. Some patients' speech patterns might be similar to the speech pattern used in their favorite TV programs, while some patients use echolalia, a repetition of another person's speech. ${ }^{10}$ These communication issues can affect oral health care in and out of the dental office. At home, lack of verbal communication and understanding between the parent/guardian and the patient with ASD can lead to problems with oral self-care such as toothbrushing and flossing. This lack of communication skills can become a serious problem when the patients experience oral pain, because they might be unable to communicate the pain to their caregiver. In the dental office, a lack of communication between the patient and provider could be potentially dangerous during procedures when the patient feels pain or is scared and cannot communicate these sensations, but might act out as a consequence. Dental care providers therefore need to be aware that the use of special behavior management strategies such as the use of visual communication means and the use of rewards and behavior-shaping strategies might be needed.

The second diagnostic characteristic, impairment of social interactions, encompasses more than merely language deficits. Persons with ASD demonstrate issues with relating to others socially and have difficulties recognizing that others have feelings and thoughts that are different from their own. ${ }^{12}$ Patients with ASD may be content in being alone or they may ignore others' requests for attention. They may not establish eye contact, or they may not pay attention to others or seek out others' attention..$^{10}$ Because of these deficits, persons with ASD are less likely to develop social relationships, and if they do, the relationships are likely to revolve around the person with ASD's interests. ${ }^{10}$ In a dental setting, impairment of social interactions would clearly hinder developing a patient-provider relationship. These patients may not make eye contact with the provider or respond when the provider tries to talk to them or explains a procedure. They may even feel uncomfortable with another person in such close proximity to themselves. These difficulties may challenge dental care providers when providing care for a patient with ASD.

The third diagnostic characteristic associated with ASD is aversion to change and restricted and repeated behavior patterns. Patients with ASD may have difficulty if their routine is changed ${ }^{11}$ and may repeat actions over and over again. They might, for example, limit the types of food they eat, beverages they drink, or behaviors in which they engage. This aversion to change can cause problems when coming to a dental office for the first time, and even when returning for dental visits, because the dental procedures might change and the change may be unbearable for a patient with ASD. Patients with ASD may also have difficulties with changing sounds and with various smells during their dental treatment. Providing dental care for patients with ASD can therefore be challenging for dental care providers.

In consideration of these specific challenges when treating patients with ASD, the first objective of our study was to analyze general and pediatric dentists' attitudes and professional behavior concerning providing care for patients with ASD and specifically their considerations of the three sets of characteristics when treating these patients. The second objective focused on assessing how well these respondents felt prepared by their dental education to treat these patients. Wolff et al. surveyed third- and fourth-year dental students about their experiences with patients with mental retardation during their dental education and found that 50.8 percent of fourth-year dental students had never treated a patient with mental retardation and 68.2 percent had spent less than five hours providing clinical treatment for these patients. ${ }^{13}$ In addition, 22.2 percent of these students had received less than one hour of didactic education about treating patients with mental retardation, and 68.2 percent had received five hours or less. Another study, published in 2003, found that only one-fourth of general dentists reported hands-on educational experiences in dental school with children with special health care needs. ${ }^{14}$

In addition to assessing the amount of time spent on education about how to provide care for these patients, other studies have examined how well providers feel their dental school prepared them to treat patients with special needs. Dao et al. found that the majority of their respondents felt not at all well prepared or not well prepared to treat patients with special needs or mental retardation. ${ }^{8}$ A study by Smith et al. published in 2005 compared responses of dental students and dental alumni on questions related to treating underserved patients. They found that 41.3 percent of responding dental students felt that their dental education had prepared them well to treat patients with disabilities, while only 35 percent of the dental alumni felt well prepared $(\mathrm{p}<.001) .{ }^{15}$ Another study of fourth-year dental students found that nearly 75 percent responded they were "not at all" or "a little" prepared to provide care for patients with mental retardation. ${ }^{13}$ In an attempt to add to the findings of these studies, the second objective 
of our study was to assess how well prepared general and pediatric dentists feel concerning providing care for patients with autism.

The third objective was to explore the relationship between dental education and professional attitudes and behavior concerning treating patients with ASD. Prior research supports the hypothesis that there might be a relationship. For example, DeLucia and Davis showed in 2009 that dental students' attitudes towards patients with developmental disabilities changed after a two-hour lecture on managing these patients. ${ }^{16}$ After the lecture, the students' expectations of the general and dental capabilities of patients with developmental disabilities were higher than they were before the lecture and they remained high even in a six-month and one-year follow-up survey. While the lecture did not change the students' comfort level with treating these patients, previous experiences with patients with intellectual disabilities were positively associated with their comfort level. In 2005, Dao et al. reported that the perceived quality of education about treating these patients was significantly correlated with more positive responses about treating special needs patients, such as actually providing care for these patients and being more confident when treating them. ${ }^{8}$ Similarly, Wolff et al. found that the more experiences students had with persons with mental retardation, the more positive their attitudes were towards these patients, the more they appreciated these patients' dental needs, and the more aware they were of the capabilities of patients with mental retardation. ${ }^{13}$

In addition to demonstrating how attitudes can change, previous studies have examined the effect of experiences on professional behavior. In 2005, Dao et al. reported that general dentists who were well prepared to treat pediatric patients with special needs did in fact treat more of these patients in a week than general practitioners who were not well prepared. ${ }^{8}$ These dentists also treated higher percentages of patients covered by Medicaid and from a lower socioeconomic background if they felt better prepared by their dental education to treat patients with special needs. Similarly, Casamassimo and Seale reported in 2003 that general practitioners with clinical and didactic experiences with special needs children in dental school were significantly more likely to report that they treated these patients "often" or "very often" and were also more likely to desire additional training concerning the treatment of these patients. ${ }^{14}$ Based on these results, our study examined whether there is a relationship between general and pediatric dentists' educational experiences concerning providing care for patients with ASD and their professional attitudes and behavior concerning those patients.

\section{Methods}

This research was approved by the Institutional Review Board for the Health Sciences at the University of Michigan (\#H03-00000742-R2).

Data were collected from a random sample of general dentists who were members of the Michigan Dental Association (MDA). A total of 162 dentists responded to a survey mailed to 500 randomly chosen members of the MDA (response rate: 32 percent). In addition, 500 surveys were mailed to randomly selected members of the American Academy of Pediatric Dentistry (AAPD), and 212 members responded (response rate: 42 percent). Table 1 provides an overview of the background and practice characteristics of these two groups of respondents. The majority of dentists in both groups were predominantly male (general dentists: 83 percent vs. pediatric dentists: 70 percent; $p=.003$ ) and European American (general dentists: 93 percent vs. pediatric dentists: 86 percent; $p=.09$ ). The average age of the general dentists was fifty years; it was forty-six years for the pediatric dentists $(\mathrm{p}=.001)$.

The data were collected with a mailed survey that was sent to a random sample of 500 members of the MDA and to a random sample of 500 members of the AAPD. The dentists received a letter explaining the study and encouraging them to participate, as well as the survey and a self-addressed stamped return envelope in which they could return the completed survey to the researchers.

Both surveys assessed the respondents' background, practice characteristics, and educational experiences regarding providing care for patients with special needs, mental retardation, and autism. In addition, the dentists' professional attitudes and professional behavior concerning providing care for these patient populations were assessed. The respondents' professional behavior was examined by asking them in general how many patients with these characteristics they treated and then more specifically which behavior management strategies they used. Both surveys were revised versions of a survey used by Dao et al. in their exploration of general dentists' responses regarding patients with special needs. ${ }^{8}$

The data were analyzed with SPSS (Version 16.0). ${ }^{17}$ Descriptive data such as frequencies, percentages, and means were provided to give an overview 
Table 1. Study respondent characteristics, by percentage of total respondents in each category (general dentists and pediatric dentists)

\author{
General Dentists _ Pediatric Dentists
}

$\mathrm{p}$

Background Characteristics

Are you male or female?

Male

Female

$83 \%$

$17 \%$

50

How old are you? (average age in years)

What is your ethnicity/race?

African American

American Indian

Asian

European American

Latino/a/Other

Practice Characteristics

Number of years practicing dentistry (average)

Practice location

Rural

Moderate-sized city

Large city

Small town

Suburb

Employment situation

Solo practice

Partnership/group practice

Associateship

Academic appointment

Salaried employee: HMO

Salaried employee: hospital

Salaried employee: other

Percentage of time spent in

Office practice

Dental school

Hospital

Percentage of patients from

High SES

Average SES

Low SES

Percentage of patients covered by

Medicaid

Private pay

Insurance

Number of hours worked per week

Number of patients seen in average week

Total

Under 16 years of age

With special needs

With mental retardation

With autism spectrum disorders

Do you treat patients with autism? Yes.

$3 \%$

$1 \%$

$1 \%$

$93 \%$

23

$13 \%$

$38 \%$

$5 \%$

$14 \%$

$31 \%$

$66 \%$

$24 \%$

$7 \%$

$1 \%$

0

0

$1 \%$

$96 \%$

$2 \%$

0

$21 \%$

$61 \%$

$18 \%$

$3 \%$

$26 \%$

$69 \%$

33

58

13

2

2

1

$32 \%$
$70 \%$

$30 \%$

46

$2 \% / 1 \%$
21

.139

$4 \%$

0

$5 \%$

$86 \%$

$4 \% / 1 \%$

$<.001$

$8 \%$

$34 \%$

$22 \%$

$34 \%$

$43 \%$

$5 \%$

$15 \%$

$16 \%$

$8 \%$

$7 \%$

$5 \%$

$80 \%$

$<.001$

$6 \%$

.009

$<.001$

$20 \%$

.737

$<.001$

$<.001$

$28 \%$

$<.001$

.005

$<.001$

$51 \%$

.004

127

$<.001$

$<.001$

$<.001$

$<.001$

$<.001$

$<.001$

Note: Percentages may not total $100 \%$ becase of rounding. 
of the findings. Independent sample t-tests and chisquare tests were used to compare the responses of the general and pediatric dentists. Pearson correlation coefficients were computed to analyze the relationships between the educational experiences and the professional attitudes and behavior. A p value of $<0.05$ was considered statistically significant.

\section{Results}

Before discussing the findings concerning respondents' professional attitudes, behaviors, and educational experiences concerning treating patients with ASD as well as the relationship between respondents' educational experiences and professional attitudes and behavior, a more detailed description of the respondents' background and practice characteristics will be given. As can be seen in Table 1, the pediatric dentists were less likely to be male (70 percent vs. 83 percent; $p=.003$ ) and were on average about three and a half years younger ( 46 vs. 50 years; $p=.001$ ) than the general dentists. While both groups of providers were predominantly European American (general dentists: 93 percent vs. pediatric dentists: 86 percent), there was a tendency for the pediatric dentists to be more likely to be non-white (14 percent vs. 7 percent; $p=.09$ ) than the general dentists. Concerning practice characteristics, the responding pediatric and general dentists did not differ significantly in how long they had practiced dentistry. However, the pediatric dentists were much less likely to have their practice in a rural setting ( 3 percent vs. 13 percent) or in a moderate-sized city ( 8 percent vs. 38 percent), and were much more likely to have their practice in a large city ( 34 percent vs. 5 percent) or in a suburb (34 percent vs. 31 percent) compared to the general dentists $(\mathrm{p}<.001)$. While the general dentists were more likely to work in a solo practice (66 percent vs. 43 percent) or in a partnership or group practice (24 percent vs. 5 percent) compared to the pediatric dentists, the pediatric dentists were more likely to have an academic appointment (16 percent vs. 1 percent) or associateship (15 percent vs. 7 percent) or to be a salaried employee, whether in an HMO ( 8 percent vs. 0 ), hospital ( 7 percent vs. 0 ), or other employed position ( 5 percent vs. 1 percent; $\mathrm{p}<.001$ ). Accordingly, the general dentists reported spending the majority of their time in an office practice (96 percent vs. 80 percent), while higher percentages of the pediatric dentists said they spend their time in a hospital setting (11 percent vs. $0 ; \mathrm{p}<.001)$ or dental school (6 percent vs. 2 percent; $p=.009$ ).

Concerning the numbers and types of patients treated, the data showed that the pediatric dentists treated significantly more patients in an average week than the general dentists (127 vs. $58 ; \mathrm{p}<.001)$. The pediatric dentists were more likely to treat patients from lower socioeconomic backgrounds ( 28 percent vs. 18 percent; $\mathrm{p}<.001)$ and were less likely to treat patients from average socioeconomic backgrounds (49 percent vs. 61 percent; $p<.001$ ) compared to the general dentists. Higher percentages of the pediatric dentists accepted patients on Medicaid (27 percent vs. 3 percent; $\mathrm{p}<.001$ ) compared to the general dentists. Concerning the types of patients treated, the pediatric dentists said they treat predominantly children under sixteen years of age, while the general dentists were much less likely to treat children under sixteen years of age in an average week ( $110 \mathrm{vs.} \mathrm{thirteen} \mathrm{patients;}$ $\mathrm{p}<.001)$. The pediatric dentists said they treat more patients with special needs in an average week (ten vs. two; $p<.001)$ than did the general dentists. They also reported that they treat significantly more patients with mental retardation and autism compared to the general dentists in an average week (mental retardation: five vs. two; $p<.001$; ASD: two vs. one; $\mathrm{p}<.001)$. Overall, 89 percent of the pediatric dentists treated patients with autism, while only 32 percent of the general dentists provided care for these patients $(\mathrm{p}<.001)$.

Before analyzing whether the quality of their dental education affected the respondents' professional attitudes and behavior concerning providing care for patients with ASD, it is worthwhile to first describe these attitudes and behavior. Table 2 provides an overview of attitudinal responses of these two groups of respondents. This table shows that the pediatric dentists agreed on average more strongly with the statement "I like to treat children with ASD" than the general dentists (on a five-point answer scale with $1=$ disagree strongly and $5=$ =agree strongly: 3.35 vs. 2.36; $<$.001). In addition, the pediatric dentists were much more likely to agree with the statements "My staff is comfortable treating autistic children" (3.94 vs. 2.62; $<$.001) and "My staff is knowledgeable about treating autistic children" (3.88 vs. 2.02; $\mathrm{p}<.001)$ and were more interested in taking continuing education programs about providing care for autistic patients ( 3.28 vs. $3.01 ; p=.031)$ than the general dentists. However, both the general and pediatric dentists responded on average with a neutral response 
to the statement "Autistic children are often unable to tolerate dental treatment because of sights and sounds in the dental operatory" (3.16 vs. $3.19 ; \mathrm{p}=.785$ ). There was a slight tendency for the pediatric dentists to agree more strongly with the statement "Primary care physicians should be trained to educate the parents of autistic children about oral health care" compared to the general dentists (4.17 vs. $3.91 ; \mathrm{p}=.065)$. Finally,

Table 2. Responding general and pediatric dentists' professional attitudes and behavior concerning providing care for patients with autism spectrum disorders

\section{General Dentists Pediatric Dentists}

\section{Professional Attitudes ${ }^{\mathrm{a}}$}

I like to treat children with ASD.

I would like to take some continuing education programs about ASD.

Autistic children are often unable to tolerate dental treatment because of sights and sounds in the dental operatory.

Primary care physicians should be trained to educate the parents of autistic children about oral health care.

My staff is comfortable treating autistic children.

My staff is knowledgeable about treating autistic children.

Financial compensation for treating autistic patients is inadequate.

Professional Behavior. Please indicate if you offer:

Practices for overcoming communication issues Special visual aids for communication Rewards at the end of child's visit

Practices for overcoming social relations problems Special instructions to parents before treatment Parents can accompany their children in the operatory

Practices for overcoming aversion to change Familiarization visits before the first appointment Special scheduling arrangements Special office set-up

TV set in waiting area

TV set in operatory

Parent can bring child's favorite video

How often do you use the following techniques?

Practices for overcoming communication challenges

Visual aids

Behavior shaping with rewards

Positive reinforcement with words

Tell-show-do

Tell-show-feel

Practices for overcoming social relations problems

Letting them observe other children

Letting them observe their parents' dental treatment

Practices for overcoming aversion to change and new situations

Desensitization efforts

Behavior management strategies

Hand-over-mouth technique

Papoose board/physical restraints

Having dental assistant(s) restrain child

Having parent restrain child

Nitrous oxide inhalation

Oral sedation

General anesthesia

Refer to specialists

\begin{tabular}{|c|c|c|}
\hline 2.36 & 3.35 & $<.001$ \\
\hline 3.01 & 3.28 & .031 \\
\hline 3.16 & 3.19 & .785 \\
\hline 3.91 & 4.17 & .065 \\
\hline 2.62 & 3.94 & $<.001$ \\
\hline 2.02 & 3.88 & $<.001$ \\
\hline 3.22 & 3.75 & $<.001$ \\
\hline$\%$ yes & $\%$ yes & $p$ \\
\hline $21 \%$ & $12 \%$ & .060 \\
\hline $95 \%$ & $99 \%$ & .064 \\
\hline $30 \%$ & $34 \%$ & .363 \\
\hline $89 \%$ & $93 \%$ & .231 \\
\hline $62 \%$ & $47 \%$ & .036 \\
\hline $59 \%$ & $67 \%$ & .165 \\
\hline $8 \%$ & $18 \%$ & .052 \\
\hline $26 \%$ & $60 \%$ & $<.001$ \\
\hline $20 \%$ & $29 \%$ & .121 \\
\hline $32 \%$ & $39 \%$ & .240 \\
\hline Mean & Mean & $p$ \\
\hline 2.21 & 2.12 & .463 \\
\hline 2.33 & 2.52 & .046 \\
\hline 2.94 & 2.86 & .031 \\
\hline 2.87 & 2.89 & .724 \\
\hline 2.77 & 2.81 & .603 \\
\hline 1.83 & 2.17 & .002 \\
\hline 2.37 & 1.43 & $<.001$ \\
\hline 2.20 & 2.51 & .010 \\
\hline 1.16 & 1.08 & .157 \\
\hline 1.02 & 1.84 & $<.001$ \\
\hline 1.38 & 1.99 & $<.001$ \\
\hline 1.53 & 2.07 & $<.001$ \\
\hline 1.81 & 2.00 & .105 \\
\hline 1.39 & 1.75 & $<.001$ \\
\hline 1.09 & 2.09 & $<.001$ \\
\hline 2.39 & 1.39 & $<.001$ \\
\hline
\end{tabular}

aAnswers were given on a scale from $1=$ disagree strongly to $5=$ agree strongly.

${ }^{\mathrm{b}}$ Answers were given on a scale from $1=$ never to $3=$ often. 
the pediatric dentists agreed significantly more with the statement "Financial compensation for treating autistic patients is inadequate" than the general dentists (3.75 vs. 3.22; $\mathrm{p}<.001)$.

The comparison of the general and pediatric dentists' professional behavior concerning the care for patients with autism consisted of analyzing the responses to three sets of questions. The first set was concerned with the number of patients with specific characteristics treated by the two respondent groups in an average week. As mentioned in discussing the findings in Table 1, the pediatric dentists treated significantly more patients with special needs, mental retardation, and autism in an average week than did the general dentists.

The second set of behavioral indicators required the providers to indicate if they used vs. did not use certain practices related to overcoming communication challenges, social relations problems, and problems with aversion to change and new situations when treating patients with autism. Before discussing these results, it is important to revisit the finding that 89 percent of the pediatric dentists said they treat patients with autism, but that only 32 percent of the general dentists indicated that they do. The responses in Table 2 therefore were given only by those providers who had indicated they would treat these patients. Concerning the findings relevant to overcoming communication problems, the data showed a tendency that a higher percentage of the general dentists use special visual aids for communication with these children ( 21 percent vs. 12 percent; $p=.060$ ) compared to the pediatric dentists. However, practically all of the pediatric dentists said they use rewards to communicate with these patients (99 percent) compared to 95 percent of the general dentists $(\mathrm{p}=.064)$. Concerning the techniques used to overcome challenges connected with social relation issues, no difference in the percentages of responses of the general dentists and pediatric dentists was found. Both groups of respondents indicated that they use practices for overcoming social relations problems with these patients such as providing special instructions to parents before treatment or letting the parent accompany the child into the operatory. While most dentists let the parents accompany their children into the operatory, only about a third said they give special instructions to the parents of autistic children before treatment.

Concerning the practices for overcoming autistic children's aversion to change and new situations, the general dentists were more likely to offer familiarization visits before the first appointment compared to the pediatric dentists (62 percent vs. 47 percent; $p=.036$ ). About two-thirds of the dentists in both groups said they offer special scheduling arrangements, but only a minority of respondents in both groups said they have a special office setup for these patients (general dentists: 8 percent vs. pediatric dentists: 18 percent; $p=.052$ ). While the pediatric dentists were more likely to have a TV set in the waiting area (60 percent vs. 26 percent; $p<.001$ ) compared to general dentists, the two respondent groups did not differ in the probability of having a TV set in the operatory or of letting the parents bring the patient's favorite videotape.

While the second set of questions merely assessed whether providers use certain behavior management techniques, the third set of behaviorrelated questions asked how frequently they use these techniques related to the three sets of symptoms that are characteristic for children with ASD. The answers to these questions were given on a three-point answer scale with $1=$ never, $2=$ sometimes, and $3=$ often. The responses concerning the frequencies with which the dentists used techniques related to overcoming communication challenges showed that the pediatric and general dentists did not differ in the frequency with which they use visual aids, tell-show-do, or tell-show-feel. However, the pediatric dentists used behavior shaping with rewards more frequently $(2.52$ vs. $2.33 ; \mathrm{p}=.046$ ), while the general dentists were more likely to use positive reinforcement with words than pediatric dentists ( 2.94 vs. $2.86 ; \mathrm{p}=.031$ ).

Concerning the frequency with which techniques for overcoming social relations problems were used, the two respondent groups differed significantly from each other. The pediatric dentists were more likely to allow the patient to observe other children ( 2.17 vs. $1.83 ; p=.002)$ than the general dentists, while the general dentists were more likely to allow the patients to observe their parents' dental treatment than the pediatric dentists ( 2.37 vs. 1.43 ; $\mathrm{p}<.001)$. Concerning the frequency with which the two respondent groups used practices to overcome aversion to change and new situations, Table 2 shows that the pediatric dentists more frequently used desensitization efforts than the general dentists (2.51 vs. $2.20 ; p=.010)$.

The third set of questions asked about the frequency with which both groups of providers used general behavior management strategies such as pharmacological behavior management (the use of nitrous oxide, oral sedation, or general anesthesia) 
and nonpharmacological behavior management strategies such as the hand-over-mouth technique, papoose board, physical restraints, having the dental assistant restrain the child, or having a parent restrain the child. Concerning the use of nonpharmacological techniques, Table 2 shows that the pediatric dentists were more likely to use restraints, either in the form of a papoose board ( 1.84 vs. $1.02 ; \mathrm{p}<.001)$ or by having a dental assistant $(1.99$ vs. $1.38 ; \mathrm{p}<.001)$ or parent restrain the child ( 2.07 vs. $1.53 ; \mathrm{p}<.001)$, compared to the general dentists. In addition, the pediatric dentists more frequently used oral sedation ( $1.75 \mathrm{vs.}$ $1.39 ; \mathrm{p}<.001)$ and general anesthesia (2.09 vs. 1.09 ; $\mathrm{p}<.001)$ than the general dentists.

In addition to showing the professional attitudes and behavior concerning treatment of patients with autism in Table 2, we provide in Table 3 an overview of the responses concerning the respondents' educational experiences with providing care for patients with autism and other special needs. Three items inquired how well the respondents' predoctoral dental education had prepared them to treat patients with special needs, patients with mental retardation, and patients with autism. The answers to these questions were given on a five-point scale ranging from $1=$ not at all to $5=$ very well. One additional Likert-type item with answers ranging from $1=$ disagree strongly to $5=$ agree strongly inquired how much the respondents agreed with the statement "Dental school prepared me well for treating autistic children." In addition, the pediatric dentists responded to three separate questions concerning how well their graduate education had prepared them to treat patients with special needs, mental retardation, and autism. The majority of both the general dentists and pediatric dentists reported that their predoctoral dental education did not prepare them well - which was indicated with a response of 1 (not at all) or 2-for managing patients with special needs (general dentists: 66 percent vs. pediatric dentists 70 percent), mental retardation (general dentists: 71 percent vs. pediatric dentists: 71 percent), and autism (general dentists: 87 percent vs. pediatric dentists: 80 percent). Only a very small percentage of respondents in both groups reported that their predoctoral education had prepared them well or very well to provide care for these patients (patients with special needs: 8.8 percent vs. 9.1 percent; patients with mental retardation: 8 percent vs. 9 percent; patients with autism: 3 percent vs. 3 percent). While the general dentists and pediatric dentists did not differ in perceptions of their education concerning treating patients with special needs and mental retardation, the pediatric dentists were slightly less negative about their education concerning treating patients with autism ( 1.75 vs. $1.53 ; p=.017)$. On the whole, the general dentists disagreed more strongly with the statement "Dental school prepared me well for treating autistic children" (on a scale from 1=dis-

Table 3. Respondents' educational experiences concerning the treatment of patients with autism, by percentage of total respondents in each category

\begin{tabular}{|c|c|c|c|c|c|c|}
\hline & Respondents & $1 \& 2$ & 3 & $4 \& 5$ & Mean & $\mathrm{P}$ \\
\hline \multicolumn{7}{|c|}{$\begin{array}{l}\text { How well did your predoctoral dental education } \\
\text { prepare you for managing patients with }\end{array}$} \\
\hline \multirow[t]{2}{*}{ Special needs ${ }^{\mathrm{a}}$} & General dentists & $66 \%$ & $25 \%$ & $9 \%$ & 2.06 & .928 \\
\hline & Pediatric dentists & $70 \%$ & $21 \%$ & $9 \%$ & 2.07 & \\
\hline \multirow[t]{2}{*}{ Mental retardation ${ }^{a}$} & General dentists & $71 \%$ & $21 \%$ & $8 \%$ & 1.93 & .413 \\
\hline & Pediatric dentists & $71 \%$ & $20 \%$ & $9 \%$ & 2.02 & \\
\hline \multirow[t]{2}{*}{ Autism $^{\mathrm{a}}$} & General dentists & $87 \%$ & $11 \%$ & $3 \%$ & 1.53 & .017 \\
\hline & Pediatric dentists & $80 \%$ & $17 \%$ & $3 \%$ & 1.75 & \\
\hline \multirow{2}{*}{$\begin{array}{l}\text { Dental school prepared me well for } \\
\text { treating autistic children. }{ }^{b}\end{array}$} & General dentists & $86 \%$ & $12 \%$ & $3 \%$ & 1.54 & .042 \\
\hline & Pediatric dentists & $82 \%$ & $12 \%$ & $6 \%$ & 1.74 & \\
\hline \multicolumn{7}{|c|}{$\begin{array}{l}\text { How well did your graduate dental education } \\
\text { prepare you for managing patients with }\end{array}$} \\
\hline Special needs ${ }^{\mathrm{a}}$ & Pediatric dentists & $5 \%$ & $8 \%$ & $88 \%$ & 4.46 & - \\
\hline Mental retardation ${ }^{\mathrm{a}}$ & Pediatric dentists & $4 \%$ & $10 \%$ & $86 \%$ & 4.43 & - \\
\hline Autism $^{\mathrm{a}}$ & Pediatric dentists & $10 \%$ & $16 \%$ & $74 \%$ & 4.15 & - \\
\hline \multicolumn{7}{|c|}{$\begin{array}{l}\text { aAnswers ranged from } 1=\text { not at all to } 5=\text { very well. } \\
\text { bAnswers ranged from } 1=\text { disagree strongly to } 5=\text { agree strongly. }\end{array}$} \\
\hline \multicolumn{7}{|c|}{ Note: Percentages may not total $100 \%$ because of rounding. } \\
\hline
\end{tabular}


agree strongly to $5=$ agree strongly: 1.54 vs. 1.74 , $\mathrm{p}=.042$ ) compared to the pediatric dentists. While the general dentists did not respond to the questions about the quality of graduate education about managing patients with these three characteristics, the pediatric dentists indicated that their graduate education had prepared them rather well for managing patients with special needs (on a scale from $1=$ not at all well to $5=$ very well: 4.46 ), patients with mental retardation (4.43), or patients with autism (4.15).
The last set of analyses were concerned with the correlations between the providers' educational experiences concerning treating patients with these characteristics and their background and practice characteristics, attitudes toward providing care for these patients, and professional behavior in this area. Table 4 shows that the older the dentists were, the less well they were prepared by their predoctoral dental education to treat patients with special needs $(\mathrm{r}=-.23 ; \mathrm{p}<.001)$, patients with mental retardation

Table 4. Correlations between respondents' educational experiences and practice characteristics and professional attitudes

\begin{tabular}{|c|c|c|c|c|c|c|c|}
\hline & \multirow[t]{2}{*}{$\begin{array}{l}\text { Dental school } \\
\text { prepared } \\
\text { me well }\end{array}$} & \multicolumn{3}{|c|}{$\begin{array}{l}\text { How well did your predoctoral } \\
\text { dental education prepare you } \\
\text { for managing patients with }\end{array}$} & \multicolumn{3}{|c|}{$\begin{array}{l}\text { How well did your graduate } \\
\text { education prepare you for } \\
\text { managing patients with }\end{array}$} \\
\hline & & $\begin{array}{l}\text { Special } \\
\text { Needs }\end{array}$ & $\begin{array}{c}\text { Mental } \\
\text { Retardation }\end{array}$ & Autism & $\begin{array}{l}\text { Special } \\
\text { Needs }\end{array}$ & $\begin{array}{c}\text { Mental } \\
\text { Retardation }\end{array}$ & Autism \\
\hline Age & $-.12 *$ & $-.23^{* * *}$ & $-.21^{* * *}$ & $-.19^{* * *}$ & -.04 & $-.35^{* * *}$ & $-.73 * * *$ \\
\hline \multicolumn{8}{|l|}{ Practice Characteristics } \\
\hline $\begin{array}{l}\text { Number of years practicing dentistry } \\
\text { Percentage of time spent in }\end{array}$ & $-.11^{*}$ & $-.23^{* * *}$ & $-.20^{* * *}$ & $-.17^{* * *}$ & -.04 & $-.31^{* * *}$ & $-.33^{* * *}$ \\
\hline $\begin{array}{l}\text { Office practice } \\
\text { Hospital }\end{array}$ & $\begin{array}{l}-.08 \\
.10^{*}\end{array}$ & $\begin{array}{l}-.11^{*} \\
.09\end{array}$ & $\begin{array}{l}-.12^{*} \\
.11^{*}\end{array}$ & $\begin{array}{l}-.12^{*} \\
.18^{* * *}\end{array}$ & $\begin{array}{l}-.07 \\
.02\end{array}$ & $\begin{array}{l}-.06 \\
.09\end{array}$ & $\begin{array}{l}-.08 \\
.12\end{array}$ \\
\hline $\begin{array}{l}\text { Percentage of patients from } \\
\text { Average SES } \\
\text { Low SES }\end{array}$ & $\begin{array}{l}-.08 \\
.06\end{array}$ & $\begin{array}{l}-.17^{* * *} \\
.13^{*}\end{array}$ & $\begin{array}{l}-.18^{* * *} \\
.15^{* *}\end{array}$ & $\begin{array}{l}-.22^{* * * *} \\
.18^{* * *}\end{array}$ & $\begin{array}{l}-.02 \\
-.03\end{array}$ & $\begin{array}{l}-.06 \\
.01\end{array}$ & $\begin{array}{l}-.01 \\
.02\end{array}$ \\
\hline $\begin{array}{l}\text { Percentage of patients covered by } \\
\text { Medicaid } \\
\text { Private pay } \\
\text { Insurance }\end{array}$ & $\begin{array}{l}.12^{*} \\
-.12^{*} \\
-.06\end{array}$ & $\begin{array}{l}.15^{* *} \\
-.03 \\
-.13^{*}\end{array}$ & $\begin{array}{l}.17^{* * *} \\
-.03 \\
-.15^{* *}\end{array}$ & $\begin{array}{l}.22^{* * *} \\
-.08 \\
-.16^{* *}\end{array}$ & $\begin{array}{l}-.04 \\
-.02 \\
.07\end{array}$ & $\begin{array}{l}.07 \\
-.02 \\
-.04\end{array}$ & $\begin{array}{l}.07 \\
-.03 \\
-.03\end{array}$ \\
\hline Number of hours worked per week & .07 & $.11^{*}$ & .09 & .04 & -.02 & $.15^{*}$ & $.16^{*}$ \\
\hline $\begin{array}{l}\text { Professional Attitudes }^{\text {a }} \\
\text { I like to treat children with ASD. } \\
\text { I would like to take some continuing } \\
\text { education programs about ASD. }\end{array}$ & $\begin{array}{l}.19^{* * *} \\
.11^{*}\end{array}$ & $\begin{array}{l}.09 \\
.11^{*}\end{array}$ & $\begin{array}{l}.12^{*} \\
.11^{*}\end{array}$ & $\begin{array}{l}.18^{* * *} \\
.10\end{array}$ & $\begin{array}{l}-.04 \\
-.06\end{array}$ & $\begin{array}{l}.28^{* * *} \\
.10\end{array}$ & $\begin{array}{c}.25^{* * *} \\
.06\end{array}$ \\
\hline $\begin{array}{l}\text { Autistic children are often unable to } \\
\text { tolerate dental treatment because } \\
\text { of sights and sounds in the dental } \\
\text { operatory. }\end{array}$ & .02 & $.11^{*}$ & $.14^{*}$ & .05 & .10 & .07 & .02 \\
\hline $\begin{array}{l}\text { Primary care physicians should be trained } \\
\text { to educate the parents of autistic children } \\
\text { about oral health care. }\end{array}$ & .04 & .06 & .03 & .02 & -.04 & .08 & .07 \\
\hline $\begin{array}{l}\text { My staff is comfortable treating autistic } \\
\text { children. }\end{array}$ & $.18^{* * *}$ & .08 & $.13^{*}$ & $.22^{* * *}$ & -.01 & $.34^{* * *}$ & $.31^{* * *}$ \\
\hline $\begin{array}{l}\text { My staff is knowledgeable about treating } \\
\text { autistic children. }\end{array}$ & $.20^{* * *}$ & .05 & .10 & $.21^{* * *}$ & -.06 & $.36^{* * *}$ & $.34^{* * *}$ \\
\hline $\begin{array}{l}\text { Financial compensation for treating } \\
\text { autistic patients is inadequate. }\end{array}$ & -.08 & -.06 & -.04 & -.06 & -.05 & -.07 & -.08 \\
\hline \multicolumn{8}{|c|}{$\begin{array}{l}\text { aAnswers to these questions were given on a scale from } 1=\text { disagree strongly to } 5=\text { agree strongly. } \\
\text { bAnswers to these questions were given on a scale from } 1=\text { not at all well to } 5=\text { very well. }\end{array}$} \\
\hline
\end{tabular}


$(\mathrm{r}=-.21 ; \mathrm{p}<.001)$, and patients with autism $(\mathrm{r}=-.19$; $\mathrm{p}<.001)$. The same relationships were found between the responses concerning graduate educational experiences and these characteristics. The younger the respondents were, the better their graduate education had prepared them to treat patients with mental retardation $(\mathrm{r}=-.35 ; \mathrm{p}<.001)$ and patients with autism $(r=-.73 ; p<.001)$. This pattern of findings was also replicated for the relationships between the responses to these educational items and the number of years of having practiced dentistry. In addition, the degree to which the respondents had been well prepared by their predoctoral dental education to treat patients with special needs, mental retardation, and autism was significantly correlated with the percentage of patients they treated from a low socioeconomic background and with the percentage of patients on Medicaid.

Table 4 provides an overview of the correlations between the educational experiences concerning managing patients with the different characteristics and the respondents' attitudes. It is crucial to note that the correlations between graduate educational experiences and the variables of interest in Table 4 and Table 5 only refer to the data from the pediatric dentists because the general dentists did not have any graduate education experiences in pediatric dentistry. The correlations between the predoctoral educational experiences and the constructs of interest were computed with the combined data of the pediatric and the general dentists because both groups had these experiences. Table 4 shows that the better prepared the respondents were by their predoctoral dental education to manage patients with special needs, the more they agreed with the statement "I like to treat children with ASD" $(\mathrm{r}=.19 ; \mathrm{p}<.001)$ and the more they were interested in taking some continuing education programs about treating patients with ASD $(r=.11 ; p=.036)$. In addition, the better they were prepared by their predoctoral dental education and their graduate education to treat patients with mental retardation and autism, the more they agreed with the statements "My staff is comfortable treating autistic children" and "My staff is knowledgeable about treating autistic children."

Table 5 provides an overview of the correlations between educational experiences and specific professional behaviors concerning providing care for patients with autism. Concerning the first set of behavioral indicators, there are significant correlations between the degree to which the respondents indicated that their predoctoral dental education had prepared them well for managing patients with special needs, mental retardation, and autism and how many patients with special needs, mental retardation, and autism the providers treated. The better the respondents felt prepared, the more likely they were to treat these patients. Concerning the frequencies with which the respondents used certain practices related to overcoming communication challenges, social relations problems, and aversion to change and new situations, there were relatively few significant relationships. The more pediatric dentists perceived that their graduate education had prepared them well for managing patients with special needs, mental retardation, and autism, the more frequently they used behavior shaping with rewards, positive reinforcement with words, and desensitization efforts as practices for overcoming patients' aversion to change and new situations.

\section{Discussion}

This study included two groups of respondents (general dentists and pediatric dentists) because pediatric dentists might be seen as being better prepared and more likely to treat special needs patients than general dentists. This assumption was supported by several findings. The data showed that the pediatric dentists' attitudes concerning providing care for patients with special needs and autism were significantly more positive than the attitudes of the general dentists. The pediatric dentists did agree more strongly with statements such as "I like to treat children with ASD," "I would like to take some continuing education programs about ASD," and "Financial compensation for treating autistic patients is inadequate" compared to the general dentists. In addition, the results concerning the respondents' professional behavior in this context were consistent with these attitudinal findings and with the stereotypic assumption that pediatric dentists might be better suited to provide care for special needs patients. The data showed that the pediatric dentists treated on average more patients with special needs, mental retardation, and autism in an average week compared to the general dentists. Additionally, while the majority ( 89 percent) of the pediatric dentists reported that they treat patients with autism, only about a third ( 32 percent) of the general dentists said they provide care for these patients. These findings 
Table 5. Correlations between respondents' educational experiences and professional behavior concerning providing care for patients with autism

\begin{tabular}{|c|c|c|c|c|c|c|c|}
\hline & \multirow[t]{2}{*}{$\begin{array}{l}\text { Dental school } \\
\text { prepared } \\
\text { me well }\end{array}$} & \multicolumn{3}{|c|}{$\begin{array}{l}\text { How well did your predoctoral } \\
\text { dental education prepare you } \\
\text { for managing patients with }\end{array}$} & \multicolumn{3}{|c|}{$\begin{array}{l}\text { How well did your graduate } \\
\text { dental education prepare you } \\
\text { for managing patients with }\end{array}$} \\
\hline & & $\begin{array}{l}\text { Special } \\
\text { Needs }\end{array}$ & $\begin{array}{c}\text { Mental } \\
\text { Retardation }\end{array}$ & Autism & $\begin{array}{l}\text { Special } \\
\text { Needs }\end{array}$ & $\begin{array}{c}\text { Mental } \\
\text { Retardation }\end{array}$ & Autism \\
\hline \multicolumn{8}{|l|}{ Number of patients seen in average week } \\
\hline Total & .02 & -.07 & -.06 & -.06 & -.06 & .06 & 0 \\
\hline Under 16 years of age & .08 & -.07 & -.03 & .01 & -.07 & .12 & .06 \\
\hline With special needs & $.20^{* * *}$ & $.21^{* * *}$ & $.20^{* * *}$ & $.12^{*}$ & -.02 & $.24^{* * *}$ & $.20^{* *}$ \\
\hline With mental retardation & $.20^{* * *}$ & $.17^{* *}$ & $.18^{* * *}$ & $.14^{*}$ & -.02 & $.14^{*}$ & .11 \\
\hline With autism spectrum disorders & $.14^{* *}$ & .10 & .10 & .09 & -.02 & $.16^{*}$ & .08 \\
\hline \multicolumn{8}{|c|}{ How often do you use practices related to overcoming ${ }^{c}$} \\
\hline \multicolumn{8}{|c|}{ Communication challenges } \\
\hline Behavior shaping with rewards & .09 & .10 & .09 & .10 & $.22 * *$ & $.25^{* * *}$ & $.26^{* * *}$ \\
\hline Visual aids & .06 & .05 & .05 & .08 & .07 & .08 & .14 \\
\hline Positive reinforcement with words & -.00 & .01 & -.02 & -.04 & .12 & .13 & $.17^{*}$ \\
\hline Tell-show-do & -.08 & -.05 & -.08 & -.11 & .01 & .05 & .08 \\
\hline Tell-show-feel & -.02 & -.03 & -.04 & -.03 & .08 & .11 & .10 \\
\hline \multicolumn{8}{|l|}{ Social relations problems } \\
\hline Letting them observe other children & .09 & $.14^{*}$ & .10 & .07 & .07 & .12 & .10 \\
\hline $\begin{array}{l}\text { Letting them observe their parents' } \\
\text { dental treatment }\end{array}$ & -.01 & .10 & .09 & .03 & .07 & .09 & .10 \\
\hline \multicolumn{8}{|l|}{ Aversion to change and new situations } \\
\hline Desensitization efforts & -.02 & .02 & 0 & 0 & .14 & $.19^{* *}$ & $.22^{* * *}$ \\
\hline \multicolumn{8}{|c|}{$\begin{array}{l}\text { aAnswers to this question were given on a scale from } 1=\text { disagree strongly to } 5=\text { agree strongly. } \\
\text { bAnswers to these questions were given on a scale from } 1=\text { not at all well to } 5=\text { =very well. } \\
\text { 'Answers to these questions were given on a scale from } 1=\text { never to } 3=\text { often. }\end{array}$} \\
\hline${ }^{*} \mathrm{p}<.05, * * \mathrm{p}<.01, * * * \mathrm{p}<.001$ & & & & & & & \\
\hline
\end{tabular}

are noteworthy because they need to be considered in connection with the fact that the numbers of pediatric dentists in the United States are not sufficient to provide care for all patients with special needs. It seems therefore crucial to rethink this stereotype of pediatric dentists as providers of care for patients with special needs and to accept that general dentists and dental hygienists need to provide care for these patients if the access problems for these patients are to be eased. ${ }^{1}$

Changing general dentists' attitudes and behavior in this context could benefit from educational changes. The findings in our study were consistent with earlier results found by Dao et al. regarding general dentists, ${ }^{8}$ by Smith et al. regarding dental students and dental alumni, ${ }^{15}$ and by Wolff et al. regarding dental students. ${ }^{13}$ Only a small percentage of respondents in all studies reported that their predoctoral dental education had prepared them well or very well to provide care for patients with special needs, mental retardation, and autism. However, all studies found that the better the respondents perceived their dental education to be, the more likely they were to have positive attitudes and/or show positive behavior concerning providing care for these patients.

In consideration of these findings, it is important to point out that recent changes in the accreditation standards for dental and dental hygiene programs require these programs to ensure that their "Graduates must be competent in assessing the treatment needs of patients with special needs." ${ }^{18}$ These changes will hopefully contribute to an increased coverage of these issues in predoctoral and dental hygiene curricula. Improved dental and dental hygiene education might then result in more positive professional attitudes and behavior in this context. This research and related findings clearly showed that the better prepared the respondents were by their predoctoral dental education about the treatment of patients with special needs, the more positive their attitudes were. ${ }^{8,13}$

Consistent with these findings concerning the relationships between dental education and 
professional attitudes are the results concerning the relationships between educational experiences and professional behavior. Our data showed that the perceived quality of dental education about the treatment of these patients was significantly related to the numbers of these patients the respondents treat. It might be helpful in this context to reflect on the process of dental education and which educational efforts can be most successfully be used to optimally prepare future dental care providers for their professional responsibilities concerning these patient groups. Casamassimo and Seale offered some suggestions concerning the type of educational efforts that might be most useful in this context when he reported that the more hands-on/lecture experiences with special needs children general practitioners had during their dental education, the more likely they were to treat these patients "often" or "very often."14

In addition to reflecting on the process of how this education could be optimally structured, it seems also important to reflect on the content that should be communicated. Given the great variety of special needs that dental providers encounter, it might be helpful to reflect on a general approach to this issue. One general approach to how future providers can be prepared optimally for providing care for patients with special needs could be to introduce them to a "bottom up/top down" approach when educating these future providers about how to manage patients with certain special needs.

This approach can be exemplified by discussing the specific findings concerning which behaviors were used by the respondents when managing patients with ASD. However, a general explanation of this approach needs to be given first. The "bottom up" part of this approach would start by informing students about the general characteristics of patients with ASD. In the context of treating patients with ASD, these general characteristics would include the three sets of symptoms discussed above: the patients' general problems with communication, with social relations and interactions, and with repetitive behavior and aversion to change. Understanding these general characteristics would allow the students to gain a better understanding of the underlying issues that these patients have. The "top down" component then focuses on the specific demands in the dental setting that these patients face. For example, patients and providers need to communicate about expectations and upcoming procedures. This communication is affected by the first group of symptoms that charac- terize patients with ASD: their problems with verbal communication. In addition, patients and providers would under optimal circumstances develop a certain amount of rapport, which would be part of the second set of symptoms that characterize patients with ASD: their issues with social relationships. Finally, coming to the dental setting confronts patients with various sounds, smells, and experiences with touch and other sensations such as pain or discomfort. These experiences touch on the third set of characteristics of patients with ASD: their aversion to change and their preference for repetitive behavior.

In other words, understanding first which general characteristics patients from certain groups have would provide the basis (the "bottom up" background information) to approach these patients. In addition, understanding secondly the specific characteristics of, for example, the dental situation (the "top down" information) would complete the picture and define the challenges that will be encountered when treating a patient with ASD. The third step would then be to develop the behavior management strategy that can successfully overcome the challenge that was identified when using the "bottom up" information and considering the "top down" needs of the situation.

A concrete example would be the following: "bottom up" information provides a provider with an understanding of the fact that patients with ASD have problems with verbal communication but tend to respond well to visual information. The "top down" analysis of the demands in a given dental situation would, for example, result in providers' realization that they need to communicate to the patient how to brush his or her teeth. The next step would be for this provider to reflect on the match between the "bottom up" and "top down" information and to develop a strategy to allow the provider to perform the task at hand - in this case, to teach the patient how to brush his or her teeth. One strategy would be to use visual information such as story boards that visually and gradually depict the behaviors that the patient should perform and thus communicate to the patient what is expected. Another strategy could be to use behavior shaping by continuously giving rewards to the patient when appropriate behaviors are shown. Collaborating with the patients' primary caregiver on developing appropriate strategies might help the provider in these specific efforts.

Using this "bottom up/top down" approach can guide the interpretation and discussion of the findings in this study concerning which specific behavior 
management strategies were used by the respondents. For example, the fact that only 12 percent of the responding pediatric dentists and 21 percent of the responding general dentists use special visual aides for communication with these patients could be interpreted as a clear indicator of a lack of understanding of the specific characteristics of these patients, in particular their problems with verbal communication and their potentially more positive response to visual information. Another example that would reflect the lack of understanding of the relevance of the second characteristic - the problems with social interactions - could be seen in the fact that quite a number of respondents in this study reported that they let these patients observe other children or their parents in the dental office. If providers understand the "bottom up" information that patients with ASD have problems with social relations, they might not choose to let these children observe other children or their parents in the dental setting because patients with ASD are less likely to relate to others and thus are less likely to benefit from such observations.

Finally, "bottom up" information about the fact that patients with ASD have problems with environmental changes and new environments could inform providers about how to structure the dental environment for a patient with ASD. For example, providers could develop strategies that consider these "bottom up" characteristics and the "top down" demands of the dental situation and would result in having the patient with ASD always be treated in the same operatory and/or by the same provider who wears the same clinic coat, etc. Having the suction on when the patient enters the operatory in order to not introduce a new sound during an appointment might be another strategy that could be developed on the basis of such a "bottom up/top down" approach. The fact that only a few respondents (18 percent of the pediatric dentists and 8 percent of the general dentists) reported that they use a special office set-up when providing care for patients with ASD could be an indicator that their background understanding of the characteristics of these patients might be limited.

\section{Conclusions}

Given the access to care problems for patients with special needs, ${ }^{1}$ it seems crucial to gain a better understanding of how these problems could be ameliorated. Our data showed that the respondents' professional attitudes and behavior concerning the treatment of patients with autism and other special needs could be improved. The results also showed that both groups of respondents did not perceive their predoctoral dental education as having prepared them well to provide care for patients with special needs or specifically with autism. The fact that there were clear relationships between the quality of educational experiences and professional attitudes and behavior is noteworthy and should challenge dental educators to reflect on how to best provide solid educational programs in this context.

Our data also showed that the specific behavior management strategies chosen by the providers might not be the most beneficial strategies when managing patients with ASD. A general "bottom up/top down" approach was proposed as a way to guide dental care providers in the development of optimal behavior management strategies.

\section{Acknowledgments}

We want to thank the American Academy of Pediatric Dentistry and the Michigan Dental Association for providing us with the address labels for the mailing of the surveys. We also want to express our gratitude to Dr. Thomas J. Bouwens, who collected data from the general dentists, and Dr. Neerrajah Ramaswami, who collaborated on the collection of data from the pediatric dentists.

\section{REFERENCES}

1. Oral health in America: a report of the surgeon general. NIH Publication 00-4713. Rockville, MD: U.S. Department of Health and Human Services, National Institute of Dental and Craniofacial Research, National Institutes of Health, 2000:7.

2. Kanner L. Autistic disturbances of affective contact. Nervous Child 1943;2:217-50.

3. American Psychiatric Association. Diagnostic and statistical manual of mental disorders, 4th ed. Washington, DC: American Psychiatric Publishing, 2000.

4. Rutter M. Incidence of autism spectrum disorders: changes over time and their meaning. Acta Paediatr 2005;94:2-15.

5. Centers for Disease Control and Prevention. Prevalence of autism spectrum disorders: autism and developmental disabilities monitoring network, six sites, United States, 2000. MMWR Surveill Summ 2007;56(1):1-11.

6. Centers for Disease Control and Prevention. Prevalence of autism spectrum disorders: autism and developmental disabilities monitoring network, 14 sites, United States, 2002. MMWR Surveill Summ 2007;56(1):12-28.

7. Green D, Flanagan D. Understanding the autistic dental patient. Gen Dent 2008;56(2):167-71.

8. Dao LP, Zwetchkenbaum S, Inglehart MR. General dentists and special needs patients: does dental education matter? J Dent Educ 2005;69(10):1107-15. 
9. Marshall J, Sheller B, Williams BJ, Mancl L, Cowan C. Cooperation predictors for dental patients with autism. Pediatr Dent 2007;29(5):369-76.

10. Johnson CP, Myers SM, Council on Children with Disabilities. Identification and evaluation of children with autism spectrum disorders. Pediatrics 2007;120(5):1183-215.

11. Waldman HB, Perlman SP, Wong A. Providing dental care for the patient with autism. J Calif Dent Assoc 2008;36(9):662-70.

12. Baron-Cohen S. The cognitive neuroscience of autism. J Neurol Neurosurg Psychiatry 2004;75(7):945-8.

13. Wolff AJ, Waldman HB, Milano M, Perlman SP. Dental students' experiences with and attitudes toward people with mental retardation. J Am Dent Assoc 2004;135: $353-7$.
14. Casamassimo PS, Seale NS. Access to dental care for children in the United States: a survey of general practitioners. J Am Dent Assoc 2003;134:1630-40.

15. Smith CS, Ester TV, Inglehart MR. Dental education and care for underserved patients: an analysis of students' intentions and alumni behavior. J Dent Educ 2006;70(4):398-408.

16. DeLucia LM, Davis EL. Dental students' attitudes toward the care of individuals with intellectual disabilities: relationship between instruction and experience. J Dent Educ 2009; 73(4):445-53.

17. SPSS Inc. SPSS 16.0 student version for Windows (SA). New York: Prentice Hall, 2008.

18. Commission on Dental Accreditation. Accreditation standards for dental education programs. Chicago: American Dental Association, 2007. 